\title{
Criterios de la marcación técnica en lexicografía: el léxico taurino (adjetivos y verbos) en el $D R A E$
}

\author{
Ramón Morillo-Velarde Pérez \\ Universidad de Córdoba
}

Diccionario, no eres tumba, sepulcro, féretro, túmulo, mausoleo, sino preservación, fuego escondido, plantación de rubíes, perpetuidad viviente de la esencia, granero del idioma.

(Pablo Neruda, Oda al Diccionario)

\section{INTRODUCCIÓN: EL LÉXICO NOMENCLÁTOR Y LA MARCACIÓN TÉCNICA}

La lexemática y la semántica estructural vienen aprovechándose de una distinción, establecida, si mis noticias son exactas, por Coseriu (1977) y seguida después por casi todos los semantólogos, entre el léxico "estructurado" y el léxico "nomenclátor". Es decir, entre el léxico común y las terminologías -científicas o populares-, llamadas también léxicos especiales e incluso “lenguas especiales” (Rodríguez Díez 1981).

No hace falta insistir demasiado en la relevancia que tal distinción alcanza para la técnica lexicográfica. Más tarde intentaremos pasar revista sumaria a algunos de los problemas que a esta plantea la existencia de este tipo de léxico mediante el análisis del tratamiento que el $D R A E$ realiza de unos de estos léxicos especiales (el léxico taurino), pero antes es conveniente fijar, siquiera sea brevemente, el estatuto lin- 
güístico de los fenómenos de esta naturaleza, o, lo que es lo mismo, discutir el fundamento último de la distinción entre los dos tipos de léxico.

La distinción entre léxico estructurado y léxico nomenclátor se fundamenta (según Coseriu 1977 y Aldestein 2004) en las siguientes diferencias básicas entre uno y otro:

- en el léxico nomenclátor las palabras se presentan como meras sustitutas de las realidades nombradas, a las que se refieren de manera unívoca, univocidad que rara vez se da en el léxico común.

- Las oposiciones que se establecen entre piezas léxicas en el seno de las nomenclaturas se corresponden, por tanto, con oposiciones entre los designata y tales oposiciones habrán de ser, por naturale$\mathrm{za}$, excluyentes, en el sentido de que un objeto pertenece a una categoría u otra de las referidas, pero no a ambas a la vez. En el léxico común, por el contrario, las oposiciones son de naturaleza inclusiva, en las que un término no marcado suele englobar a su opuesto marcado, como el significado no marcado del lexema hombre engloba el del lexema marcado mujer (Lyons 1971).

- En última instancia, estas diferencias remitirían al hecho de que las estructuraciones reveladas por el léxico nomenclátor son estructuraciones de la realidad que el léxico se limita a reflejar como un espejo, en tanto las estructuraciones del léxico común se imponen a la realidad desde la lengua y tienen, por tanto, carácter arbitrario.

- Finalmente, desde una óptica estrictamente formal, el léxico nomenclátor es básicamente neológico, aunque accidentalmente pueda presentarse como patrimonial, en tanto que el léxico estructurado es justo al contrario: de base patrimonial, puede, en ocasiones, presentarse como neológico.

Desde mi punto de vista, el problema fundamental de la distinción coseriana es que está concebida y formulada en términos excesivamente aristotélicos, esto es, entendiendo que "léxico estructurado" y "léxico nomenclátor" son conceptos radicalmente separados y opuestos por notas diferenciadas, el total de las cuales viene a ser el conjunto de con- 
diciones necesarias y suficientes que un conjunto dado de palabras ha de cumplir para ser adscrito a una u otra categoría del léxico. Pero, desde esa perspectiva, está claro que no todo aquello a lo que comúnmente se aplica el nombre de nomenclatura o que designamos como léxicos especiales $-o$ lenguas especiales- $o$ incluso como lenguaje científicotécnico, cumple por igual todas las condiciones descritas por Coseriu.

Mirando las cosas desde la lexicografía, que es lo que ahora nos interesa, el léxico nomenclátor de la lengua está compuesto, entre otras, por todas aquellas acepciones que en los diccionarios suelen ir precedidas de marcas diferentes de las gramaticales, geográficas, o sociales, es decir, de aquellas que informan sobre la categoría gramatical de las palabras, su ámbito geográfico o temporal de uso u origen o su posible nivel de estigmatización social. Son muchas las marcas de este tipo, conocidas como marcas técnicas (Azorín Fernández 1992, Fajardo Aguirre 1994 y 1996-1997, Porto Dapena 2002), que aparecen en los diccionarios. El DRAE, por ejemplo, trae en su vigésima segunda edición un total de 51 marcas técnicas, después de una drástica reducción de las más de 140 de las anteriores (Azorín Fernández 1992), repartidas en cinco categorías: ciencias experimentales, ciencias humanas, cultura, economía y producción e instituciones, que engloban 19160 acepciones pertenecientes a 12120 entradas, esto es, el $12,6 \%$ y el $13,7 \%$ del total de acepciones y entradas (151962 y 88431, respectivamente).

Como es obvio, ni tales cantidades, ni los porcentajes subsiguientes suponen, ni por aproximación, el total del léxico nomenclátor de la lengua, y no ya sólo porque la reducción de marcas haya rebajado la cantidad de entradas o acepciones que las tienen (de hecho no hay diferencias significativas en el número de apariciones de las marcas entre las dos últimas ediciones, con 19189 acepciones marcadas en la vigésima primera, frente a las 19160 de la actual, pese a la reducción de las marcas), sino porque la macroestructura del diccionario no recoge la totalidad del léxico especializado, o porque no poca cantidad de ese léxico aparece recogido sin marca, es decir, porque no aparece reflejado como tal en su microestructura.

He ahí las tres clases de problemas que el léxico especializado causa a los lexicógrafos: determinar qué parcelas de lo real son objeto de un 
tratamiento cognitivo lo suficientemente diferenciado como para merecer una marca específica en un diccionario; establecer el léxico especializado propio, y fijar cuándo un dato léxico concreto debe llevar marca señaladora de su pertenencia a un subconjunto particular y diferenciado del léxico nomenclátor general de la lengua. Habría aún un cuarto tipo de problema que atañe a la clase de definición lexicográfica de que deberían ser objeto las acepciones encuadrables en el ámbito del léxico agrupado bajo esta clase de marcas: si una definición de carácter enciclopédico que pudiera trasladarse desde cualquier texto o manual especializado, o la simple manifestación del significado general en un lenguaje llano y asequible a un usuario no introducido en el dominio técnico de que se trate.

Ocurre, no obstante, que los subconjuntos léxicos que aparecen dotados de marcas técnicas en el DRAE no conforman un todo homogéneo, como lo prueba el hecho de que éstas se engloben en las cuatro categorías a que antes nos hemos referidos: ciencias experimentales, ciencias humanas, cultura, economía y producción e instituciones. Es conveniente saber, además, que las marcas técnicas han conocido en la lexicografía académica una profunda reorganización entre la vigésima primera y la vigésima segunda edición del diccionario, empezando por su propia denominación, apellidadas en aquella de materia y nivel, subdividida, a su vez, en tres categorías: profesiones y disciplinas, variantes socialmente marcadas y variantes desprestigiadas. En cuanto a las marcas relativas a profesiones y disciplinas, aparecían agrupadas en $\mathrm{Fi}$ losofía, Religión, Ciencias del hombre, Ciencia y técnica y otros. Ni qué decir tiene que, desde un punto de vista racional, la clasificación de la vigésima segunda edición mejora mucho la anterior, máxime si se tiene en cuenta que, además de otros, la categoría de Ciencia y técnica era un auténtico cajón de sastre que englobaba no sólo las terminologías científicas, sino también las de los distintos oficios que componían una lista de 13 marcas -entre las que se incluyen algunas tan pintorescas como la gnomónica, ciencia que enseña a hacer relojes solares, o la propia relojería-. Claro que tampoco se entiende muy bien por qué motivo esa lista de oficios, trasladada con justicia a la categoría de economía y producción, se ha visto reducida en la vigésima segunda edi- 
ción a la marca de Carpintería. De lo que seguramente se trataba, como ha sido reclamado en más de una ocasión (Azorín Fernández 1992: 448), es de adaptar las marcas técnicas a los tiempos que corren, racionalizando su número y su organización y actualizándolas en conexión con el mundo de referencia del público al que el diccionario se dirige, no de reducir arbitrariamente esa lista de marcas. En cualquier caso, si los redactores del diccionario entienden que las marcas técnicas de oficio deben desaparecer, opinión perfectamente legítima, deberían hacerlo todas. Lo que no tiene ningún sentido es usar marcas que después no se han incluido en el árbol de marcas técnicas de la edición en CDRom y que sólo aparecen en el listado alfabético de abreviaturas de la edición en papel; este fallo es tanto más relevante cuanto que las marcas son mucho menos útiles en la edición en papel que en la electróni$\mathrm{ca}$, donde se pueden realizar funciones de búsqueda de la totalidad del léxico marcado con cada una de ellas, lo que sería excesivamente trabajoso en aquella. Este hecho es el que se ha producido con la mayoría de las marcas "de oficios", como la albañilería (marcada ahora como Constr.). Tampoco está muy claro el criterio de suprimir la marca, manteniendo la acepción, sobre todo, tras advertir en los preliminares ("Advertencias... 2.3") que las marcas aparecen siempre y cuando el uso del término no se haya hecho general. ¿Hay que pensar, entonces, que la actual acepción 6 de encañonar "Encajar un pliego dentro de otro", que en la edición vigésima primera llevaba la marca Encuad., ha generalizado su empleo?

En el fondo, la mayoría de estos problemas se plantean por la heterogeneidad del estatuto léxico-semántico que presenta el léxico nomenclátor, derivado de la propia heterogeneidad de los dominios cognitivos que se engloban en él. No es lo mismo, en efecto, la terminología de las ciencias experimentales y de la tecnología derivada de ellas, que la de las ciencias humanas, aun cuando haya entre ellas notables afinidades. Éstas serán mucho menores con algunos de los sectores léxicos incluidos en el nodo apellidado como cultura, que engloba los ámbitos de Artes, divididas en artes visuales y escénicas, astrología y astronomía, creencias (entre las que se incluyen ciencias ocultas, mitos y fábulas y religión), deportes, sistemas y medios de comunicación (edición e im- 
prenta y medios de comunicación de masas) y ocio, que comprende aficiones y espectáculos. En la primera se incluye sólo la cinegética y en la segunda la tauromaquia.

Quizás el primer criterio de heterogeneidad entre toda esta masa de léxico se encuentre en el carácter predominantemente neológico o patrimonial de las terminologías propias de estos sectores del conocimiento y la técnica; y subrayo lo de predominantemente, pues en ningún momento se pretende dar a entender que haya terminologías que sean patrimoniales o neológicas de manera exclusiva. Lo que sí es evidente es que ciertos campos del saber recurren con preferencia al neologismo para conformar su banco de términos y que, incluso cuando tales términos proceden del fondo patrimonial del idioma, las voces que de él se toman sufren un fuerte desplazamiento semántico, las más de las veces de origen metafórico, que las hace funcionar como auténticos neologismos. Por el contrario, hay terminologías cuya base es, ante todo, patrimonial y cuyos términos lo son sin un desplazamiento semántico excesivo con respecto al uso no especializado, o formada por procedimientos designativos usuales en la lengua, o de derivación y composición totalmente regulares. De manera accidental, cualquier unidad de cualquier sistema terminológico, sea neológico o patrimonial, puede pasar a formar parte del léxico común -basta con que cualquier circunstancia fortuita atraiga la atención sobre el campo del saber al que pertenece o sobre su designata en concreto, como ocurre con ciertos términos propios de la bioquímica, como colesterol-pudiendo penetrar en el idioma de manera más o menos profunda; en el caso, sin embargo, de los sistemas terminológicos de base patrimonial, los trasvases son más naturales y frecuentes, por la simple razón de que tales sistemas suelen pertenecer a ámbitos del saber que forman parte del horizonte cotidiano de los hablantes de la zona, región o ámbito (Coseriu 1967) de los que ellos también forman parte.

La circunstancia que acabamos de reseñar impide afirmar la inexistencia de una verdadera solución de continuidad entre los sistemas terminológicos específicos de base patrimonial y el léxico nomenclátor común de la lengua (Ahumada Lara 2002: XI); pero como, por otra parte, tampoco se puede afirmar que la haya entre estas terminologías y 
las de base neológica (pues pueden admitir también extensiones metafóricas de voces patrimoniales), está claro que, desde esta perspectiva, el léxico nomenclátor se nos presenta como un continuo en el que resulta en extremo difícil, cuando no imposible, establecer fronteras categoriales, hecho que puede convertir en muy arriesgada la decisión que inevitablemente ha de tomar el lexicógrafo sobre si se deben colocar o no marcas ante este tipo de léxico.

\section{EL LÉXICO TAURINO EN EL DRAE}

No obstante lo anterior, la moderna ciencia cognitiva ofrece algunas vías metodológicas con que poner puertas a este campo, la principal de las cuales es la teoría de los prototipos que permite distinguir el léxico central de un dominio cognitivo, esto es, el que ha de aparecer en los diccionarios como necesariamente provisto de la marca identificadora de ese dominio, y el léxico periférico que, por poseer un carácter más general o usos menos específicos, puede aparecer sin ningún tipo de marca.

En aplicación de la perspectiva cognitiva a que acabamos de referirnos puede ser útil el análisis del tratamiento que, de un dominio cognitivo prototípico entre los dotados de sistema terminológico de índole patrimonial, hace el que también es el prototipo de diccionario de la lengua española, esto es el $D R A E$. El dominio cognitivo elegido es el del léxico de la tauromaquia. El carácter prototípico de entre los sistemas terminológicos de base patrimonial de este léxico procede, en primer lugar, de su origen hispánico y vinculado, por tanto, casi en exclusiva a la lengua española, lo que lo hace refractario a cualquier tipo de neologismo procedente de otras lenguas, dado que la fiesta del toro sólo se da en lugares de habla española, salvo Portugal y el sur de Francia, donde lo hace por influjo español. Por otra parte, constituye en el árbol de marcas de la edición electrónica del diccionario académico la única rama del nodo espectáculos, lo que aboga en favor de su carácter prototípico. Ha de señalarse también, como justificación de la existencia de una marca específica para el léxico taurino, aparte de su importancia en la vida cultural del mundo hispánico, el alto grado de permeabilidad entre el vocabulario o el lenguaje taurino en general y la lengua 
común, ya que aquel se convierte en fuente de constantes extensiones metafóricas en ésta que enraizan profundamente en ella, de manera que, desde hace tiempo, viene señalándose su mutua influencia (Cossío 1941-1961, De Torre 1974 y 2002, Amorós 1990, Martín Zorraquino 1997 o Abellá Martín 1996). Precisamente esa permeabilidad hace deseable su análisis desde la perspectiva de la selección del léxico marcado y, por tanto, considerado en su origen como uso técnico, en relación con el léxico de uso general, y en qué punto una extensión metafórica del uso técnico hace que éste abandone su ámbito específico y se integre en aquel.

El léxico marcado como propio de la tauromaquia (marca taurom.) está formado en la vigésima segunda edición del $D R A E$ por 195 acepciones repartidas en 181 entradas. Erraríamos, sin embargo, si pensáramos que es esa la totalidad del léxico taurino. Las 195 acepciones del $D R A E$ son muy pocas a la luz de las 4507 voces que recoge el Diccionario ilustrado de términos taurinos (Nieto Manjón 1987) o las 5180 del Diccionario Espasa de términos taurinos (Nieto Manjón 1996). Pero no hace falta ir tan lejos: cualquier vocabulario de los muchos a que se puede acceder a través de Internet son bastante más nutridos que el académico. Así, el de la página Portal Taurino (www.portaltaurino.com) contiene 495 entradas, superando las 500 acepciones; el de la Plaza de Toros del Puerto (http://www.terra.es/personal5/tntcoyotemax/vocabulario.htm\#abc) tiene 350, e incluso el bilingüe de Tim Hardman (www.mundotaurino.org), de la página Mundo Taurino, basado en la Barnaby Conrad's Encyclopedia of Bullfighting (1962) llega a las 358 entradas. Claro que seguramente la virtud no está de ninguno de los dos lados y ni el diccionario ignora tantos términos como parece, ni es oro o alamar todo lo que en lo otros léxicos reluce. Para resolver la cuestión de manera ordenada vamos a clasificar los términos marcados en categorías morfológicas dividiendo tales categorías en subdominios cognitivos, cotejando para cada subdominio las entradas del $D R A E$ con los de distintos léxicos electrónicos, analizando los términos de éste que no aparecen en aquellos y las posibles razones de su exclusión. Ello nos dará pie a tratar los problemas que la selección del léxico específico de terminologías patrimoniales plantea a la técnica lexicográfica. 
El léxico marcado de la tauromaquia en la vigésima segunda edición del DRAE consta de 103 sustantivos propios o adjetivos sustantivados, 57 verbos y 19 adjetivos.

\subsection{AdJETIVOS}

Los adjetivos presentes en el DRAE marcados como pertenecientes al léxico de la tauromaquia se agrupan en torno a dos subdominios cognitivos: los que describen aspectos y circunstancias de la lidia, y los que describen a los toros. El primero comprende: afarolado, ayudado, bajo, derecho, natural, revolero, tentón y tendida. El léxico del Portal taurino recoge, además de los anteriores: atravesada, delantero, estatuario, gregoriana, lagartijera y taurino. Lógicamente, todas las entradas de estos adjetivos se encuentran también en el DRAE, pero las acepciones que de ellas se recogen nada tiene que ver con el léxico de la tauromaquia, con la excepción de taurino, que aparece sin marca, quizás porque se entiende como parte del léxico común. Una explicación parecida ayuda a entender la ausencia de estocada atravesada o puyazo delantero, que pueden entenderse como usos análogos a los generales de estos adjetivos, sin que merezcan, por tanto, la consideración de unidades terminológicas propias de la tauromaquia. No sucede lo mismo con estatuario: "Pase en el que el torero se queda quieto y levanta la muleta para que pase el toro"; gregoriana: "armadura de hierro que utilizan los picadores para proteger la pierna", así llamada por haber sido introducida por Gregorio Gayo y lagartijera: "Media estocada de efecto fulminante", de la que fue un consumado ejecutor el diestro cordobés Lagartijo y de ahí su nombre. Se trata, posiblemente de voces de uso poco generalizado y que, por tanto, no pueden tener cabida en un inventario de la índole del diccionario académico.

Los adjetivos relativos a la descripción del toro se pueden, a su vez, clasificar en tres grupos diferentes: adjetivos que describen el toro por su pelaje, edad y aspecto general; adjetivos que describen al toro por sus astas (encornadura), y, finalmente, adjetivos que describen el comportamiento del toro en la lidia. Del primer grupo se recogen en la compilación académica ensabanado: "Dicho de una res: Que tiene negras u oscuras la cabeza y las extremidades, y blanco el resto del cuerpo"; meano: 
"Dicho de un toro: Que tiene blanco el pelaje de la zona genital", voz, por cierto, que se incorpora al diccionario en esta edición; y nevado: "dicho de un toro: Que, siendo de color uniforme, tiene multitud de manchas blancas". El léxico del Portal taurino, sólo en la letra a, trae los siguientes: acaramelado, acarnerado, acochinado, albahio, albardado, aldinegro, aleonado, alto de agujas, alunarado, amachorrado, ancho, anteado, añejado, aparejado, apelado, apretado, arromerado, arrosalado, asardado y azabache. De ellos, están presentes en la compilación académica: acaramelado: "Que tiene el color propio del caramelo (II azúcar fundido)"; acarnerado: "Dicho de un caballo o de una yegua: Que tiene arqueada la parte delantera de la cabeza, como el carnero"; albahio: "Dicho de una res vacuna: De color blanco amarillento"; albardado: Dicho de una res vacuna o de otro animal: Que tiene el pelo del lomo de diferente color que los demás del cuerpo"; aleonado: "leonado, de color rubio oscuro, semejante al pelo del león"; alunarado: "Dicho de una res berrenda: Cuyas manchas son redondas, como grandes lunares"; ancho; y apelado: "Dicho de dos o más caballerías o toros: Del mismo pelo o color". Faltan por completo, o las acepciones que se recogen no guardan relación con el aspecto físico de los toros: acochinado: "El toro cuya línea, prescindiendo de los cuernos recuerda la de los cerdos por su excesiva gordura"; aldinegro: "El toro retinto y castaño que tiene negro el pelo de su mitad inferior en toda longitud"; amachorrado: "El toro berrendo en el que las manchas oscuras se presentan grandes y aisladas"; anteado: "Toro con manchas arrosetadas de su mismo color, más oscuro"; añejado: "Toro pasado de edad, viejo para la lidia"; aparejado: "berrendo con listón blanco en el lomo"; apretado: "Se llama apretado de carnes al toro gordo y musculado"; arromerado: "Toro cárdeno claro"; arrosalado: "Toro salinero o sardo que tiene los lomos tan claros y brillantes que se aproximan al color rosa"; asardado: "El toro castaño entrepelado" y azabache: "El toro negro brillante y aterciopelado".

Más llamativo es el hecho de que el DRAE, entre los adjetivos que describen al toro por la morfología de sus astas, solo recoja escobillado: "Dicho de un toro: Que tiene los pitones astillados en la punta". Otro de los vocabularios virtuales consultados, el de El Diccionario del toro (www.toroslidia.com), recoge: 
Abrochado. Dícese del toro con las puntas de los cuernos apretadas o cerradas.

Acapachado. Con tendencia marcada a capacho.

Acaramelado. Coloración del cuerno que se presenta en toda su extensión, adquiriendo tonalidad más oscura en la punta. Es típica de las pintas coloradas, salineras y jaboneras.

Astiblanco. Coloración blanca intensa del cuerno desde la cepa al comienzo del pitón, que suele ser negro.

Astifino. Cuernos delgados desde la cepa, terminando en un pitón muy fino y afilado. Normalmente estas cornamentas suelen tener bastante longitud.

Astigordo. Cuernos gruesos en la cepa, adelgazan ligeramente en la pala, y suelen terminar en puntas romas. Estos cuernos suelen ser más cortos.

Astillado. Cuando el pitón presenta hebras parcialmente desprendidas, en sentido longitudinal, que semejan una astilla.

Astillano. Cuando los cuernos nacen paralelos al suelo y no se desvían en toda su trayectoria.

Astinegro. Color oscuro o negruzco del cuerno desde la cepa hasta el pitón, sin diferenciarse el pitón de la pala.

Astiverde. Coloración del cuerno con tonos verdosos en la cepa y comienzo de pala del cuerno. Esta coloración del cuerno es la más infrecuente.

Bizco. Cuando un pitón está más alto que otro. Se les llama siempre bizcos del pitón que tienen más caído.

Brocho. Cuando los cuernos aparecen apretados, o bien cierran las puntas, quedando éstas más o menos paralelas al suelo.

Corniabierto. Cuando los cuernos tienen una cuna muy ancha y crecen abiertos y separados.

Cornialto. Cuando los cuernos nacen por encima de la línea media del testuz.

Corniapretado. Cuando los cuernos se dirigen un poco hacia adelante al cerrar. Suelen formar un ángulo en el pitón de $45^{\circ}$ con respecto a la línea del suelo.

Cornibajo. Cuando los cuernos nacen por debajo de la línea media del testuz.

Cornicorto. Cuernos de escasa longitud, en comparación con el volumen del animal. 
Cornidelantero. Cuando los cuernos nacen en la parte delantera del testuz y hacia delante. Prácticamente sólo se da en ejemplares de casta navarra (en extinción). No suele usarse esta denominación en cuanto a la inserción del cuerno, pues más bien se refiere a la forma de los cuernos, no al nacimiento; es decir, cuando los cuernos se dirigen hacia delante.

Cornipaso. Cuando los cuernos se dirigen hacia arriba, luego se curvan hacia fuera, y finalmente vuelven para atrás.

Cornitrasero. Cuando los cuernos nacen por detrás de la línea de prolongación de la nuca en el hueso frontal.

Cornivuelto. Cuando los cuernos se dirigen hacia arriba y finalmente vuelven para atrás, sin curvarse hacia los lados.

Cubeto. Cuando las puntas de los cuernos crecen hacia dentro, de modo que el animal tiene dificultad de herir.

Despitonado. Despitorrado, despuntado.

Despitorrado. Cuando se rompe la punta de uno o los dos pitones, quedando rota pero no roma. Pueden tener punta si pierden sólo la vaina o estuche córneo del pitón. Despitonado, despuntado. Despuntado. Despitonado, despitorrado.

Gacho. Cuando los cuernos crecen hacia abajo, apuntando hacia el suelo.

Mocho. Cuando se pierde la totalidad del cuerno o la mayoría del mismo.

Mogón. Cuando se pierde la punta normal del cuerno, apareciendo ésta redondeada y roma, y faltando bastante sustancia.

Playero. Cuando los cuernos aparecen abiertos y muy separados, creciendo hacia afuera.

Tocado. Animales bizcos en que la desituación del pitón caído es muy poco manifiesta. Algunos autores denominan tocado cuando las puntas se dirigen un poco hacia arriba.

Veleto. Cuando los cuernos se dirigen hacia afuera, e inmediatamente se dirigen hacia arriba.

Zurdo. Desigualdad de longitud de un cuerno con respecto al otro por alteraciones del crecimiento.

De ellos aparecen en el diccionario académico sin marca: astifino: "Dicho de un toro: De astas delgadas y finas"; brocho: "Dicho de una 
res ovina: Que tiene los cuernos muy cortos"; cornalón: "Dicho de un toro o de una vaca: Que tiene muy grandes los cuernos"; corniabierto: "Dicho de un toro o de una vaca: Que tiene los cuernos muy abiertos o separados entre sí"; corniapretado: "Dicho de un toro o de una vaca: Que tiene los cuernos muy juntos o recogidos"; corniveleto: "Dicho de un toro o de una vaca: Cuyos cuernos, por ser poco curvos, quedan altos y derechos"; cubeto: "Dicho de una res bovina: Que tiene las astas caídas y muy juntas por las puntas"; despitorrado: "Dicho de un toro de lidia: Que tiene rota una o las dos astas, siempre que quede en ellas punta"; gacho: "Dicho de un buey o de una vaca: Que tiene uno de los cuernos o ambos inclinados hacia abajo"; mocho: "Dicho especialmente de un animal cornudo, de un árbol o de una torre: Que carece de punta o de la debida terminación"; mogón: "Dicho de una res vacuna: Que carece de un asta o la tiene rota por la punta".

Del grupo de adjetivos que describen las características del comportamiento del toro en la lidia, el DRAE recoge con marca: avisado: "Dicho de un toro: Que, bien por disposición natural o bien por la experiencia adquirida al ser toreado, atiende a cuanto se mueve en la plaza, dificultando y haciendo peligrosa su lidia; descastado: Dicho de un toro: Que no responde a las cualidades de su casta"; encastado: "Dicho de un toro: Que se considera típico de su casta"; pastueño: Dicho del toro de lidia: Que acude sin recelo al engaño"; pegajoso: "Dicho del toro: Que recarga las suertes y busca reiteradamente el engaño"; reservón: "Dicho de un toro: Que no muestra codicia en acudir a las suertes" y tardo: "Dicho de un toro: Que retrasa su acometida".

Sólo en la A, el léxico de El Portal Taurino recoge además: abanto: "Res que corretea mucho por el ruedo a la salida, no toma el capote y tarde en parar. Es defecto que puede no afectar a su real bravura; el toro puede ir a mejor"; abierto: "Se dice de la res que se encuentra más cerca de los medios que de las tablas"; acoceador: "El toro pusilánime que da coces"; aculado: "Toro que se pega a las tablas con la penca, en actitud defensiva. También puede decirse "apencado""; ahormado: "El toro que lleva fija la cabeza y embiste en rectitud. Puede serlo por temperamento y puede quedar ahormado como consecuencia de la lidia en varas y engaños"; ambidiestro: "El toro que se comporta y cornea por 
igual por los dos pitones"; amorcillado: "Se dice del toro que, herido mortalmente, hace esfuerzos por mantenerse de pie", y aplomado: "El toro que llega muy cansado al final de la lidia y se para". Ninguno de ellos aparece en el diccionario académico o las acepciones que se registran tienen un carácter general o están semánticamente muy alejadas de las que se recogen en el léxico de El Portal Taurino. Se exceptúa únicamente ahormado que puede considerarse incluido en la acepción 4 de ahormar: "Hacer, por medio de la muleta o de otras suertes, que el toro se coloque en disposición conveniente para darle la estocada", marcada como propia del léxico de la tauromaquia.

Obsérvese que parte del léxico recogido sin marca por el $D R A E$ se debe al carácter más general y, por tanto, no exclusivo de la terminología taurina, que en él le atribuyen a tales acepciones. En este punto, además, suele haber posturas contradictorias, o, al menos opuestas, entre la RAE y los compiladores de léxicos específicos de esta naturaleza, ya que estos tienden a aumentar el número de entradas de sus compilaciones incluyendo muchas veces en ellas aquellas voces que usan en sus ámbitos respectivos y no son de uso general, sin tener en cuenta que también pueden emplearse en ámbitos diferentes, lo que, en principio las descarta como aspirantes a estar dotadas de marcas técnicas específicas. Es lo que sucede con adjetivos como: acaramelado, que puede aplicarse a cualquier objeto que presente ese color; acarnerado, que según el $D R A E$ se dice de caballos o yeguas; o apelado, que puede también aplicarse a los equinos. En general, en estas situaciones los redactores de estos léxicos especiales se comportan, a veces, como los dialectólogos aficionados, que suelen dar cabida en sus vocabularios aquellas voces con que se topan que, simplemente, no aparecen en el diccionario académico, o lo están con una acepción ligeramente distinta a la que han encontrado en un determinado lugar, pero perfectamente catalogable como mera extensión de cualquiera de las acepciones recogidas.

En el fondo, de todo intento de acotación -horizontal o vertical- de un sector cualquiera del léxico se puede decir lo que antes se decía de las cárceles y de los hoy desaparecidos manicomios: que ni están todos los que son, ni son todos los que están. El sentido común en este caso advierte que es preferible pecar por carta de menos, que por carta de 
más, esto es, que aunque no estén todos los que son, sí sean todos los que están. Tal parece ser el criterio seguido por la lexicografía académica y, por ello, se muestra extremadamente prudente a la hora de marcar este tipo de léxico. Hay que señalar, de todas maneras, que la Academia quizá ha pecado en este caso de un exceso de precaución, que la lleva, en ocasiones a la inconsecuencia. De este modo, se marca como léxico específico de la tauromaquia ensabanado, meano y nevado, entre los adjetivos que describen el aspecto general del toro, y escobillado, entre los que describen la morfología de las astas. ¿Por qué no los otros que recoge, como albahío, alunarado, entre los primeros y astifino, brocho, corniabierto, corniapretado, corniveleto, cubeto, despitorrado, gacho o mogón, entre los segundos? Se entiende menos esa exclusión si tenemos en cuenta que en la definición de todos ellos encontramos la misma fórmula que en la de los anteriores y que justifica la presencia de marca: "Dicho de un toro o vaca" o "Dicho de una res bovina". Incluso, en el caso de despitorrado, se afirma explícitamente: "Dicho de un toro de lidia". ¿Por qué albahio, entonces se considera léxico específico de la tauromaquia y se marca como tal, y no despitorrado? Podría, tal vez, pensarse que cuando se hace constar en la definición "Dicho de un toro de lidia" se afirma implícitamente la pertenencia de la palabra que se está definiendo al léxico específico de la tauromaquia y, por tanto, la marca puede considerarse redundante y, en consecuencia, prescindible. Esto es tanto como reconocer la existencia de dos tipos de marcas: explícitas e implícitas; marcas que figuran en la lista de abreviaturas y marcas que se introducen en el cuerpo de la definición. Volveremos sobre esto más adelante.

\subsection{VERBOS}

Recoge el DRAE 56 verbos marcados como específicos del léxico taurino. Estos verbos pueden clasificarse entre aquellos que presentan sujeto no humano, es decir, que designan acciones realizadas por el toro, y aquellos que presentan un sujeto necesariamente humano, esto es, acciones realizadas por los toreros o cualquier otro interviniente en la lidia. De los primeros se recoge aconchar: "Dicho de un toro: Arrimarse a la barrera para defenderse de los toreros"; barbear: "Dicho del to- 
ro: Andar a lo largo de las tablas, rozándolas con el hocico, como olfateando y buscando la salida del ruedo"; doblar: "Dicho de un toro: Caer agonizante al final de la lidia"; derrotar: "Dar derrotes (Cornada que da el toro levantando la cabeza con un cambio brusco de dirección)"; embeber: "Dicho de un toro: Quedarse parado y con la cabeza alta cuando recibe la estocada"; encunar: "Dicho de un toro: Alcanzar al lidiador cogiéndolo entre las astas"; encampanar: "Dicho de un toro: Levantar la cabeza como desafiando"; empitonar y empuntar: "Dicho de una res: Alcanzar el bulto con los pitones"; embrocar: "Dicho de un toro: Coger al lidiador entre las astas. 4 Dicho de un toro: Enfilar a alguien con las astas"; enganchar: "Dicho de un toro: Coger al bulto y levantarlo con los pitones"; escobillar: "Dicho de un toro: Astillar los pitones, que quedan abiertos en la punta a modo de escobilla"; escupir: "Dicho de un torero o de un toro: Echarse fuera de la suerte (que, como se ve pertenece de manera simultánea a ambos grupos)"; humillar: "Dicho de un toro: Bajar la cabeza para embestir, o como precaución defensiva"; mansear, mansurrear y mansurronear: "Dicho del toro: Mostrar excesiva mansedumbre en la lidia"; puntear: "Dicho de una res vacuna: Embestir con derrotes cortos y repetidos"; tardear: "Dicho de un toro: Vacilar antes de embestir francamente" y terciar: "Dicho de un toro: Atravesarse en la suerte". Es decir 20 verbos en la totalidad de las letras del alfabeto.

El léxico de El Portal Taurino recoge tan sólo en la A abrir (plaza): "se dice que abre plaza el primer toro que sale del toril en la corrida"; aconcharse: "Cuando el toro se recuesta completamente de un costado en la barrera"; acostarse: "Cuando el toro se vence o inclina a un lado u otro al embestir"; achuchar: "Cuando el toro tapa o empuja a los toreros, pero sin llegar a empuntar"; acuchar: "Cuando el toro topa o empuja a los toreros, pero sin llegar a empuntar"; acudir: "Cuando el toro se dirige con prontitud al lugar donde se le cita"; alcanzar: "Cuando el toro llega hasta el bulto que corre delante de él"; amosquillarse: "Buscar refugio las reses vacunas en lugares sombrosos y frescos al sentirse acosadas por las moscas"; amurcar: "Dar el golpe el toro con las astas"; amusgar: "Cuando el toro mueve las orejas hacia delante y hacia atrás, con señales de querer embestir"; apencarse: "Pegar a la barrera la 
penca del rabo para esperar"; arrancar: "Cuando el toro inicia el viaje hacia el objeto que trata de embestir"; arremeter: "Cuando el toro consuma la arremetida alcanzando el bulto perseguido"; arrollar: "Arrolla el toro al diestro cuando al ir éste a consumar una suerte se le viene tan rápidamente que tiene que librar la cogida por pies. Equivale a poner en derrota. Cuando el toro derriba al lidiador y pasa por encima sin cornear"; y arropar: "En la conducción del ganado bravo, la acción de los cabestros cuando cercan y estrechan a los toros hasta que arrancan, y luego los acompañan", que llegan a 16 , casi tantos como la totalidad de los acogidos por el DRAE en este capítulo.

No hay que dejarse confundir, sin embargo, con el alto número de entradas o acepciones que figuran en el vocabulario del Portal Taurino. No pocas, en efecto, son extensiones perfectamente normales del sentido general de la palabra, que no merecen, por consiguiente ser incluidos como términos técnicos, ni tan siquiera como acepciones particulares. Es lo que sucede con verbos como acudir, achuchar, alcanzar, arremeter o arrollar; más dudoso es el caso de apencarse que el DRAE sólo recoge en su uso no pronominal, y en la acepción de "cargar con alguna obligación ingrata", y que posiblemente mereciera los honores figurar en él. Menos explicación tienen los casos de amosquillar-que el diccionario recoge como amosquilarse ("Dicho de una res: Refugiarse, huyendo de las moscas, en lugar fresco o frondoso"); amurcar ("Dicho de un toro: Golpear con las astas"); amusgar ("Dicho de un caba1lo, de un toro, etc.: Echar hacia atrás las orejas en ademán de querer morder, tirar coces o embestir") o arropar, cuya acepción 3 es: "Dicho de los cabestros: Rodear o cercar a las reses bravas para conducirlas", en los que no se explica la falta de la marca técnica correspondiente, salvo que recurramos a la consabida presencia de marcas implícitas, recurso que, no obstante, tampoco absuelve por completo a la Academia, ya que los datos lingüísticos que aparecen en las definiciones marcadas implícitamente, también aparecen en las que llevan marca explícita. Así, por ejemplo, no hay diferencia alguna en la estructura de la definición de aconchar ("Dicho de un toro: Arrimarse a la barrera para defenderse de los toreros"), que lleva marca técnica, y la de amurcar ("Dicho de un toro: Golpear con las astas"), que no la lleva. 
Los verbos de sujeto humano pueden, a su vez, clasificarse en cuatro grupos distintos: aquellos que designan acciones realizadas por el diestro, los que designan acciones realizadas por el resto de los cuadrilleros, los que refieren acciones comunes y finalmente aquellos con que se significa acciones circunstanciales o anejas a la lidia. Del primer grupo se recogen en el DRAE aguantar: "Dicho de un diestro: Adelantar el pie izquierdo, en la suerte de matar, para citar al toro conservando esta postura hasta dar la estocada, y resistiendo cuanto le es posible la embestida, de la cual se libra con el movimiento de la muleta y del cuerpo"; ahormar: "Hacer, por medio de la muleta o de otras suertes, que el toro se coloque en disposición conveniente para darle la estocada"; alegrar: "Dicho de un diestro: Excitar al toro para que acometa"; aliñar: "Preparar el toro para una suerte, sobriamente y sin adorno ni intención artística"; aliviar: "Disminuir el riesgo de las suertes, especialmente al estoquear, no estrechándose con el toro, o aprovechando sus querencias para el remate del lance"; arrimar: "Torear o intentar torear en terreno próximo al toro"; cuadrar: "Hacer que el toro coloque adecuadamente sus cuatro extremidades para entrar a matar"; doctorar: "Dicho de un matador: Tomar la alternativa"; escupir: "Dicho de un torero o de un toro: Echarse fuera de la suerte"; igualar: "cuadrar"; instrumentar: "Ejecutar las diversas suertes de la lidia"; ligar: "Ejecutar los pases o suertes sin interrupción aparente"; molinetear: "Dar molinetes (Suerte de la lidia en la que el matador gira airosamente en sentido contrario al de la embestida del toro, dándole salida)"; muletear: "Torear con la muleta"; recibir: "Dicho del diestro: Cuadrarse en la suerte de matar, para citar al toro, conservando esta postura, sin mover los pies al dar la estocada, y resistir la embestida, de la cual procura librarse con el quiebro del cuerpo y el movimiento de la muleta" y templar: "Ajustar el movimiento de la capa o la muleta a la embestida del toro, para moderarla o alegrarla".

Cualquier léxico especializado amplía, sin embargo, con facilidad esta nómina. En el léxico de El Portal Taurino, sólo en la letra A, se puede encontrar además de las formas marcadas en el DRAE: abanicar: "Antiguamente se aplicaba a un movimiento del capote a dos manos, corriendo ante el toro para sacarlo de la suerte de varas. Hoy se emplea 
mucho con la muleta como remate o adorno, de modo que la res se quede parada y el diestro termine con un desplante", término que aparece recogido con marca en el $D R A E$, aunque sólo en la acepción primera de las dos mencionadas, que pertenecería al grupo de verbos que designan acciones que pueden ser realizadas por el diestro o los cuadrilleros; adornar(se): "Esmerarse el torero en la lidia, introduciendo algún desplante o gallardía en los lances, al margen de la ejecución de las suertes"; ahondar: "Se aplica a la acción de hundir el estoque más de lo que hacía presumir la primera intención" y armar: "cuando el espada lía la muleta y monta el estoque para entrar a matar". Todos ellos, sin embargo, con excepción de abanicar pueden entenderse como meras extensiones de las formas usuales, de manera que su consideración como términos técnicos de la lidia es dudosa.

En el grupo segundo se cuentan entre los verbos recogidos con marca por el DRAE: abrir: "Separar al toro de la barrera para colocarlo en suerte"; barrenar: "Hincar la puya o el estoque revolviéndolos a modo de barrena"; burlar: "Esquivar la acometida del toro"; cuartear: "Dicho de un torero: Hacer un movimiento en curva, al ir a poner banderillas, a fin de evitar el derrote"; destroncar: "Provocar, con faenas apropiadas, reacciones bruscas o violentas del toro, para privarlo de fuerzas"; enhilar: "Ponerse delante del toro en línea recta"; tantear: "Hacer suertes al toro antes de empezar la faena para conocer su estado, intenciones o bravura"

El léxico de El Portal Taurino añade a estos, los siguientes: acorralar: "Cortar al toro todas las salidas"; colear: "El quite en el que el torero se agarra a la cola de la res forcejeando con las manos hacia atrás o a los lados"; cordillear: "Manejar la capa o muleta con los codos pegados al cuerpo, y moviendo solamente las manos o el antebrazo"; derrengar: "Lastimar demasiado el espinazo de los toros a fuerza de recortes o capotazos"; embarcar: "Prender al toro en el engaño, capote o muleta, para dominarlo"; machetear: "Acción de fatigar al toro obligándolo a cornear repetidamente el engaño"; obligar: "Forzar al toro receloso para que embista" y recoger: "Último tiempo de la suerte de capa y muleta en el que se obliga al toro a volver contra el diestro, utilizando el engaño". De ellos, el primero (acorralar) puede entenderse como mera 
extensión de la acepción $2^{\mathrm{a}}$ con que aparece en el $D R A E$ : "Encerrar a alguien dentro de estrechos límites, impidiéndole que pueda escapar", por lo que no puede considerarse tecnicismo taurino; lo mismo podría decirse de derrengar, extensión evidente de la acepción $1^{\text {a: }}$ "Descaderar, lastimar gravemente el espinazo o los lomos de una persona o de un animal" y de obligar. En cuanto a las demás, cordillear falta por completo de la nomenclatura del diccionario; las acepciones aquí consideradas de embarcar, machetear y recoger no se encuentran en él, ni a ellas puede llegarse por simple extensión semántica de alguna de las que aparecen. Finalmente, colear se recoge en idéntica acepción, pero sin marca, ya que se define (acep. $2^{\mathrm{a}}$ ): "En las corridas de toros, sujetar la res por la cola, por lo común cuando embiste al picador caído".

\section{CONCLUSIONES}

Nos encontramos, pues, ante una síntesis de las distintas categorías de exclusión de léxico del ámbito de las entradas o acepciones señaladas con marcas técnicas, sensu contrario de los criterios por los que se seleccionan las entradas o acepciones que las llevan y, a partir de las cuales pueden ser fácilmente deducidos. Esta síntesis, además, nos excusa de continuar nuestro análisis del léxico pues la generalidad de estas categorías viene demostrada por cuanto va dicho hasta ahora, de manera que de aquí podemos extraer las conclusiones fundamentales que pueden poner broche a este trabajo. Me refiero a que datos léxicos de carácter aparentemente técnico y que, como tales se recogen en compilaciones especializadas, pueden estar ausentes de un diccionario general como el $D R A E$ de varios modos:

A) Puede ocurrir que la acepción registrada en el léxico especializado falte porque se considere una simple extensión de cualquiera de las acepciones recogidas como generales, es decir porque no se la entienda como el uso de un léxico especial, sino como un uso especial del léxico, lo cual, aunque pueda parecer lo mismo, son cosas muy diferentes. Es lo que sucede con acorralar, derrengar y obligar.

B) Por ausencia de la entrada en la nomenclatura del diccionario. Esta ausencia puede estar más o menos justificada en función de la 
extensión de uso del término en cuestión dentro y fuera del ámbito de su especialización, es decir de su ambiente (zona que tiene signos específicos para objetos también específicos), ámbito (zona en que se emplea un signo porque el objeto que designa forma parte del horizonte vital de los hablantes) y región (zona donde se conoce un signo) por usar la terminología con que Coseriu (1967) clasifica los entornos. Está claro que un signo en el que ambiente, ámbito y región coincidan no es un signo que deba ser registrado más allá de los léxicos específicos y puede faltar de léxico general. Es lo que sucede, por ejemplo, con cordillear, que no aparece en el diccionario.

C) La ausencia de acepciones a las que no se puede llegar desde las acepciones de uso general recogidas en el diccionario como embarcar, machetear y recoger, presentan una situación hasta cierto punto análoga a la anterior, sólo que aquí a los criterios mencionados en ellas habrá que añadir el del grado de proximidad de dicha acepción con alguna de las recogidas, de manera que no siempre es fácil advertir si estamos ante un situación como la aquí descrita o como la referida en el punto A.

D) Finalmente, la existencia de acepciones específicas y cuya especificidad se recoge en la propia microestructura de diccionario, es decir, el caso de las ya mencionadas marcas implícitas, como sucede con colear y otros muchos que hemos visto, parece del todo censurable desde el punto de vista de la técnica lexicográfica, ya que se trata de una incoherencia para la que difícilmente se puede encontrar explicación. Se podría alegar, tal vez, que para el lector del diccionario tanto da un marca implícita como explícita, puesto que, en los dos casos, identifica la entrada o acepción como léxico especial. Y, de hecho, hay quien entiende estas expresiones como un tipo de marca o una de sus formas posibles (Fajardo Aguirre 1994: 139, Porto Dapena 2002: 251). Sin embargo, este punto de vista sólo es admisible desde una concepción "tradicional" de la lexicografía y de los diccionarios, que conciba como forma única de consulta la considerada como básica en la edición electrónica del $D R A E$, y el diccionario sólo como un libro. La tecnología moderna posibilita, no obstante, consultas de 
tipo avanzado, en las cuales puede buscase en el diccionario, entendido ahora también como herramienta informática, la relación de todas las palabras contenidas en él y dotadas de una determinada marca. No hace falta insistir en las múltiples aplicaciones (para la enseñanza, el análisis terminológico, la traductología, etc.) de este tipo de consulta. En ella, sin embargo, no aparecerán nunca las entradas o acepciones dotadas de marcas implícitas y eso implica la ausencia en los resultados de la exhaustividad necesaria en esta clase de tareas.

\section{REFERENCIAS BIBLIOGRÁFICAS}

Abella Martín, Carlos (1996): Derecho al toro. El lenguaje taurino y su influencia en lo cotidiano, Madrid, Anaya y Mario Muchnik.

AHUmada LARA, Ignacio, ed. (2002): Diccionarios y lenguas de especialidad, Jaén, Universidad de Jaén.

Aldestein, Andreína (2004): Unidad léxica y valor especilizado: estado de la cuestión y observaciones sobre su representación, Barcelona, Universidad Pompeu Fabra.

Amorós, Andrés (1990): Lenguaje taurino y sociedad, Madrid, EspasaCalpe.

Azorín FERnÁNDEZ, Dolores (1992): "El Diccionario General de la Lengua frente a los vocabularios científicos y técnicos", en Euralex 90. Proceedings, Barcelona, Biblograf, pp. 445-453.

Coseriu, Eugenio (1967): “Determinación y entorno", en Teoría del lenguaje y lingüística general. Cinco estudios, Madrid, Gredos, pp.\#282-323. (1977): Principios de semántica estructural, Madrid, Gredos.

Cossío, José María (1941-1961): Los toros. Tratado técnico e histórico, Madrid, Espasa-Calpe, 4 vols.

De Torre, José Carlos (1974): "Logos kriptós y akribía en la función del signo lingüístico", Revista de la Sociedad Española de Lingüística, 4/2, pp. 411-432.

(2002): "El léxico español de los toros", en Ignacio Ahumada (ed.), Diccionarios y lenguas de especialidad, Jaén, Universidad de Jaén, pp. 93-102.

FAJARDO AguirRe, Alejandro (1994): "La marcación técnica en la lexicografía española", Revista de Filología de la Universidad de La Laguna, 13, pp. 131-143. 
_ (1996-1997): "Las marcas lexicográficas: concepto y aplicación práctica en la lexicografía española", Revista de Lexicografía, III, pp. 31-57.

LYONS, John (1971): Introducción en la lingüística teórica, versión española de Ramón Cerdá, Barcelona, Teide.

MARTín ZoRRAQUINO, Ma Antonia (1997): "Formación de palabras y lenguaje técnico". Revista de la Sociedad Española de Lingüística, 27/2, pp. 317-339.

NiETo Manjón, Luis (1987): Diccionario Ilustrado de términos taurinos, Madrid, Espasa-Calpe.

_ (1996): Diccionario Espasa de Términos Taurinos, Madrid, EspasaCalpe.

Porto DAPENA, José-Álvaro (2002): Manual de técnica lexicográfica, Madrid, Arco/ Libros.

RodríGUEZ DíEz, Bonifacio (1981): Las lenguas especiales, Barcelona, Ariel. 